apn-nn.com/analytic/byt-ili-ne-byt-vosproizvodstvu-rossiyskoyshkoly-ekonomicheskogo-myshleniya/ (дата обращения: 11.10.2019).

9. Аршавский И. А. Роль А. А. Ухтомского - ученого и личности в создании физиологической школы Ленинградского университета // XIII Международный конгресс истории науки. М. : Наука, 1971. С. 1-14.

10. Храмов Ю. А. Научные школы в физике : моногр. Киев : Наукова думка, 1987. 399 с.

11. Гузевич Д. Ю. Научные школы как форма деятельности // Вопросы истории естествознания и техники. 2003. № 1. С. 64-93.

12. Бойко Е. С. К типологии научных школ // Социально-психологические проблемы науки. М. : Наука, 1973. С. 202-209.

13. Логинова Н. А. Феномен ученичества: приобщение к научной школе // Психологический журнал. 2000. № 5. T. 21. C. 106-111.

УДК 378.14

Науч. спец. 13.00 .08

DOI: 10.36809/2309-9380-2019-25-112-115

\section{НОРМАТИВНЫЕ АСПЕКТЫ ПРОФЕССИОНАЛЬНОЙ ПОДГОТОВКИ ПЕДАГОГОВ ФИЗИЧЕСКОЙ КУЛЬТУРЫ В СООТВЕТСТВИИ С ФГОС ВО 3++}

В статье раскрывается содержание образовательных стандартов высшего образования разных поколений с точки зрения реализации компетентностного подхода. Осуществляется сравнительный анализ нормативных документов, регламентирующих подготовку бакалавров по направлениям «Педагогическое образование», «Физическая культура», «Спорт». Современное материально-техническое обеспечение рассматривается как обязательное условие профессиональной подготовки высококвалифицированного педагога физической культуры.

Ключевые слова: профессиональная подготовка педагога физической культуры, Федеральный государственный образовательный стандарт высшего образования, образовательная деятельность, физкультурно-спортивная деятельность, спортивная подготовка, программное содержание, учебный предмет «Физическая культура».
14. Криворученко В. К. Научные школы - эффрективный путь проведения диссертационного исследования // Информационный гуманитарный портал «Знание. Понимание. Умение». URL: http//www.zpu-journal.ru/asp/scientific_ schools/2007/Krivoruchenko/ (дата обращения: 11.10.2019).

15. Чуркина Н. И. Региональные научно-педагогические школы в новой антропологической реальности // Вестн. Сиб. ин-та информ. технологий. 2018. № 3 (27). С. 119-124.

16. Чухин С. Г. Сущность и критерии сформированности научно-педагогической школы // Вестн. Ом. гос. пед. ун-та. Гуманитар. исслед. 2018. № 4 (21). С. 153-156.

17. Аронов Д. В. Научная (научно-педагогическая, творческая) школа в системе российского высшего образования // Изв. высш. учеб. заведений. Поволж. регион. Гуманитар. науки. 2014. № 2 (30). С. 236-246.

(C) Ибрагимова О. Н., 2019

\title{
NORMATIVE ASPECTS OF PROFESSIONAL TRAINING OF TEACHERS OF PHYSICAL CULTURE IN ACCORDANCE WITH EDUCATIONAL STANDARD 3++
}

The article reveals the content of educational standards of higher education of different generations from the viewpoint of implementing a competent approach. It carries out the comparative analysis of the normative documents regulating preparation of bachelors in the following fields: Pedagogical education, Physical culture, Sport. Modern logistical support is considered as an indispensable prerequisite for training a highly qualified teacher of physical culture.

Keywords: vocational training of the teacher of physical culture, Federal State Educational Standard for Higher Education, educational activity, sports activity, sports training, program content, school subject Physical culture.

Современные тенденции развития системы высшего образования характеризуются четкой формулировкой требований, предъявляемых к выпускникам образовательных учреждений в рамках направления подготовки. Нормативным документом, регламентирующим деятельность образовательных учреждений Российской Федерации, в настоящее время является Федеральный государственный образовательный стандарт (ФГОС), порядок разработки и утверждение которого устанавливаются Правительством Российской Федерации.

Высокие темпы эволюции образовательных стандартов, появившихся в системе понятий российского обра- зования в 1992 г. [1, с. 398], обусловлены потребностью государства и общества в качественной профессиональной подготовке выпускников вузов определенной сферы деятельности.

Целью данного исследования является изучение и анализ общепрофессиональных компетенций подготовки бакалавров по направлениям, характеризующим профессиональную деятельность в сфере физической культуры и спорта.

Физическая культура является частью общей культуры и направлена на физическое совершенство человека. Потребности общества, связанные с необходимостью под- 
готовки человека к более продуктивной бытовой, профессиональной и военной деятельности, явились причиной ее возникновения и развития.

Деятельность, направленную на физическое развитие и физическое совершенствование человека, в том числе и в образовательных учреждениях, до недавнего времени преимущественно осуществляли выпускники училищ олимпийского резерва, техникумов, колледжей, университетов, академий и институтов фризической культуры [2, с. 29] Так, например, в соответствии с государственным образовательным стандартом, согласованным с Министерством РФ по физической культуре, спорту и туризму, утвержденным Министерством образования РФ 2 июня 2000 г., специалиста по физической культуре и спорту должны были готовить к педагогической и тренерской деятельности во всех типах образовательных учреждений, в организациях, на предприятиях различной формы собственности, в сборных командах по видам спорта, включая сборные команды Российской Федерации; к управленческой деятельности на различных уровнях; к выполнению рекреационной и реабилитационной деятельности. Обучение в вузе осуществлялось на различных факультетах, связанных с областями физической культуры, спорта, спортивно-оздоровительного туризма. Также в регионах, не имеющих специализированных вузов, подготовку физкультурно-педагогических кадров реализовывали факультеты физической культуры в педагогических вузах [3].

С 2007 г. в России была введена двухуровневая система высшего образования, позволяющая студентам разных стран находиться в едином образовательном пространстве с идентичной системой оценивания. Ступень бакалавриата предполагала базовую подготовку к профессиональной деятельности, а магистратура предусматривалась для подготовки обучающихся к решению более сложных задач научно-исследовательской и аналитической деятельности. Федеральный государственный образовательный стандарт высшего профессионального образования (ФГОС ВПО) по направлению подготовки бакалавров 03.43 .00 «Физическая культура» (15 февраля 2010 г.) являлся частью укрупненной группы специальностей и направлений подготовки «Гуманитарные науки». Подготовка выпускника осуществлялась в рамках педагогической, тренерской, рекреационной и других видов деятельности.

Характерной особенностью Федерального государственного образовательного стандарта высшего образования (ФГОС ВО) стало внедрение термина «компетенции», представленного как комплекс общекультурных, общепрофессиональных и профессиональных характеристик выпускника. Формулировки компетенций имеют различия, отражающие специфику будущей профессиональной деятельности. Так, в направлениях подготовки 44.03.01 «Педагогическое образование» (4 декабря 2015 г.) и 49.03 .01 «Физическая культура» (7 августа 2014 г.), наряду с некоторым сходством, имеются принципиальные различия. Выпускник направления подготовки «Физическая культура» должен обеспечивать уровень подготовленности обучающихся, соответствующий требованиям ФГОС и решать педагогические задачи в рамках общеобразовательных и профессиональных образовательных орга- низаций. Эта мысль прослеживается и в общепрофессиональной компетенции ОПК-2, которой должен обладать выпускник (способностью проводить учебные занятия по базовым видам спорта с учетом особенностей обучающихся на основе положений дидактики, теории и методики фризической культуры, требований образовательных стандартов). Профессиональная компетенция ПК-4 предусматривает наличие у выпускника способности к проведению учебных занятий по физической культуре с детьми дошкольного, школьного возраста и обучающимися в образовательных организациях; к организации внеклассной физкультурно-спортивной работы. В этом поколении стандартов физическая культура и спорт были выделены в отдельную укрупненную группу, в состав которой вошли направления подготовки «Физическая культура», «Физическая культура для лиц с отклонениями в состоянии здоровья», «Рекреация и спортивно-оздоровительный туризм».

Отличительной чертой профессиональных компетенций бакалавра по направлению подготовки 44.03.01 «Педагогическое образование» является готовность выпускника к реализации образовательных программ по учебному предмету в соответствии с требованиями образовательных стандартов (ПК-1). Это означает, что в рамках педагогического образования можно осуществлять подготовку педагога по любому предмету, в том числе и по физической культуре.

Имеющиеся противоречия не были исключены и в проекте ФГОС ВО 3++. В новой версии образовательного стандарта укрупненная группа «Физическая культура и спорт» была дополнена направлением подготовки 49.03 .04 «Спорт» (25 сентября 2019 г.). Это вполне закономерно, так как в настоящее время на территории Российской Федерации более 90 государственных образовательных учреждений осуществляют обучение студентов по программам высшего образования для дальнейшей профессиональной деятельности в сфере физической культуры и спорта. Из них 14 (5 университетов, 6 академий, 3 института) федеральных государственных образовательных учреждений находятся в ведомстве Министерства спорта РФ. В соответствии с современными запросами общества эти вузы должны осуществлять подготовку тренеров по видам спорта, что в свою очередь усилит потенциал страны спортсменами высокого класса. Но предложенное содержание образовательного стандарта, по мнению специалистов сферы физической культуры и спорта, требует детального обсуждения и доработки.

Общепрофессиональные компетенции, указанные в образовательном стандарте, отражают специфику данного направления подготовки бакалавров и предусматривают формирование способности к планированию тренировочного процесса на этапах спортивной подготовки, к организации и проведению тренировочных занятий со спортсменами различного уровня квалификации в избранном виде спорта. Общепрофессиональные компетенции по направлению подготовки 49.03.01 «Физическая культура» (19 сентября 2017 г.) формируют способность проводить занятия и фризкультурно-спортивные мероприятия на основе базовых видов физкультурно-спортивной деятельности и тренировочные занятия в избранном виде спорта. Лишь 
выпускнику направления подготовки 44.03.01. «Педагогическое образование» (22 февраля 2018 г.) общепрофессиональные компетенции позволяют организовывать учебную и воспитательную деятельность обучающихся в соответствии с требованиями ФГОС.

Для выпускников по направлениям подготовки «Спорт» и «Физическая культура» образовательным стандартом предусмотрена как область профессиональной деятельности 05 «Физическая культура и спорт», так и область 01 «Образование и наука». В направлении «Педагогическое образование» предусмотрена только область профессиональной деятельности 01 «Образование и наука». Возможность подготовки выпускников не ограничивается указанными в ФГОС ВО 3++ областями профессиональной деятельности и может расширяться в другие области, при условии получения соответствующих компетенций и уровня образования. Следовательно, выпускник вуза укрупненной группы «Физическая культура и спорт» может быть подготовлен к осуществлению учебного процесса в образовательных учреждениях в соответствии с профессиональным стандартом «Педагог (Педагогическая деятельность в сфере дошкольного, начального общего, основного общего, среднего образования) (воспитатель, учитель)».

В свою очередь, выпускник направления подготовки бакалавров 44.03.01 «Педагогическое образование» может организовывать физкультурно-оздоровительную деятельность в соответствии с ФГОС дошкольного образования, в рамках двигательного режима дошкольников осуществлять педагогическую деятельность в образовательной области «Физическое развитие» [4, с. 295]. В соответствии с ФГОС начального общего, основного общего, среднего общего и среднего профессионального образования выпускник педагогического вуза также может проводить уроки по учебному предмету «Физическая культура» в образовательных учреждениях [5].

Следует отметить, что подготовка педагога физической культуры должна осуществляться в соответствии с программным содержанием, реализуемым на всех ступенях образования. Физическое воспитание, являясь педагогическим процессом, направлено на формирование теоретических знаний, умений и навыков выполнения двигательных действий, на развитие физических качеств, обеспечивающих положительную динамику физического развития и физической подготовленности. Основным средством физического воспитания является физическое упражнение, которым должен владеть педагог для создания наглядно-образного представления о технике выполнения двигательного действия. В связи с этим особого внимания заслуживает методическая и двигательная подготовка будущих педагогов по базовым видам спорта, к которым относятся плавание, гимнастика, легкая атлетика, подвижные и спортивные игры, лыжная подготовка. Например, педагог, обучая способам плавания, должен не только знать методику обучения, но и уметь плавать, чтобы видеть возможные ошибки, анализировать, подбирать способы их устранения. Базовый вид спорта - гимнастика - начинается с дошкольного возраста. Детей обучают сложнокоординированным упражнениям (лазанье по гимнастической стенке). В младших классах раздел
«Гимнастика с основами акробатики» усложняется, включая в себя кувырок, стойку на лопатках, гимнастический мост, опорный прыжок с разбега через гимнастического козла [6, с. 12]. Кроме опорных прыжков и акробатических упражнений, девочек 5-9-х классов необходимо обучать упражнениям на гимнастическом бревне, разновысоких гимнастических брусьях, а мальчиков - на гимнастической перекладине и параллельных брусьях [7, с. 23]. Рабочая программа по физической культуре для 10-11-х классов предъявляет высокие требования к уровню физической подготовленности учащихся [8, с. 61]. При этом педагог должен владеть способами установки и регулирования спортивного оборудования, приемами оказания страховки и помощи при выполнении упражнений, знать методику спортивной тренировки и развития физических качеств.

Учебный предмет «Физическая культура» в образовательных учреждениях предусматривает формирование у обучающихся теоретических знаний о физической культуре и о способах физкультурной деятельности, поэтому будущему педагогу физической культуры необходимы навыки владения педагогическими и информационно-коммуникационными технологиями, в том числе и для грамотного оформления документации планирования, анализа результатов своей профессиональной деятельности.

Оценивать возможности вуза, осуществляющего подготовку будущих педагогов физической культуры, важно с точки зрения необходимой материально-технической оснащенности, ее соответствия программному содержанию учебного предмета в образовательных учреждениях. Для профессиональной подготовки педагога физической культуры необходимо иметь игровой и гимнастический залы со спортивным оборудованием (бревно гимнастическое, гимнастический конь, разновысокие и параллельные брусья, канат для лазанья, дорожка для прыжков в длину и др.), стадион или площадку с легкоатлетической дорожкой, сектором для прыжков в длину, игровым полем для мини-футбола, баскетбольной и волейбольной площадками, полосой препятствий, лыжной трассой.

Таким образом, в результате проведенного анализа программно-нормативной документации, регламентирующей профессиональную подготовку и профессиональную деятельность будущих педагогов физической культуры, можно сделать следующий вывод.

Подготовка конкурентоспособного педагога физической культуры может осуществляться как физкультурными, так и педагогическими вузами Российской Федерации в рамках направлений 44.03 .01 «Педагогическое образование» и 49.03.01 «Физическая культура» при условии получения выпускниками соответствующих компетенций. На наш взгляд, предпочтительным является педагогическое образование, поскольку оно имеет специфику подготовки, выраженную в большем объеме часов по психолого-педагогическим дисциплинам, воспитательным практикам, связанным с различными видами педагогической деятельности в образовательном учреждении.

Обязательным условием подготовки высококвалифицированного педагога физической культуры является наличие в вузе современной материально-технической базы, соответствующей программному содержанию преподаваемого 
предмета в образовательных учреждениях. Это в большей степени касается педагогических вузов, остро нуждающихся в реконструкции и строительстве спортивных сооружений (залов, стадионов, бассейнов), необходимых не только для предметной, но и для профессионально-прикладной физической подготовки будущих педагогов.

1. Хисматулина 3. Н. Эволюция стандартов высшего образования: от ориентации на знания, умения и навыки к оценке компетенций // Вестн. Казан. технолог. ун-та. 2013. Т. 16, № 22. С. 397-401.

2. Никитушкин В.Г. Основы научно-методической деятельности в области физической культуры и спорта : учеб. М. : Советский спорт, 2013. 280 с.

3. Портал Федеральных государственных образовательных стандартов высшего образования. URL: http://fgosvo.ru (дата обращения: 01.12.2019).

4. От рождения до школы. Основная образовательная программа дошкольного образования / под ред. Н. Е. Верак- сы, Т. С. Комаровой, М. А. Васильевой. 4-е изд., перераб. М. : МОЗАИКА-СИНТЕЗ, 2017. 352 с.

5. Федеральные государственные образовательные стандарты. URL: https://fgos.ru (дата обращения: 01.12.2019).

6. Лях В. И. Физическая культура. Рабочие программы. Предметная линия учебников В. И. Ляха. 1-4 классы : учеб. пособие для общеобразоват. организаций. 5-е изд. М. : Просвещение, 2016. 64 с.

7. Лях В.И. Физическая культура. Рабочие программы. Предметная линия учебников М. Я. Виленского, В. И. Ляха. 5-9 классы : пособие для учителей общеобразоват. организаций. 4-е изд. М. : Просвещение, 2014. $104 \mathrm{c}$.

8. Лях В. И. Физическая культура. Рабочие программы. Предметная линия учебников В. И. Ляха. 10-11 классы : пособие для учителей общеобразоват. организаций. М. : Просвещение, 2015. 80 с.

(C) Матюнина Н. В., 2019
УДК $37.012 ; 111.85$

Науч. спец. 13.00.01

DOI: 10.36809/2309-9380-2019-25-115-117

\section{РАЗВИТИЕ ЭСТЕТИЧЕСКОГО ВОСПРИЯТИЯ У НАЧИНАЮЩИХ ХУДОЖНИКОВ}

В статье рассматриваются возможности развития эстетического восприятия у начинающих художников в процессе обучения изобразительному искусству. Выявляются наиболее важные аспекты эстетического восприятия. Акцентируется проблема формирования гармонического восприятия объектов и произведений искусства для активизации творческой деятельности студентов.

Ключевые слова: эстетическое восприятие, художественное творчество, эмоциональность, образность, замысел, композиция.

\section{DEVELOPMENT OF AESTHETIC PERCEPTION OF ASPIRING ARTISTS}

The article discusses the possibilities of developing aesthetic perception of aspiring artists in the process of teaching fine art. The most important aspects of aesthetic perception are revealed. The article focuses on forming harmonic perception of works of art to enhance students' creative activities.

Keywords: aesthetic perception, artistic creation, emotionality, imagery, design, composition.
В художественном творчестве первостепенное место занимает эстетическая оценка изображаемого, которая в широком понимании отражает не только эстетические принципы самого художника, но и определенной художественной эпохи. Являясь тонкой и эмоциональной стороной искусства, эстетическая оценка во многом обусловливает весь процесс становления художественного изображения, начиная от формирования первоначального замысла и заканчивая нахождением содержательной формы, позволяющей материализовать замысел в определенном композиционном решении.

Материалистическая теория познания исходит из признания существования объективной реальности и способности человека познать ее. Сознание отражает свойства и закономерности явлений, процессов, существующих независимо от него. Следовательно, образное познание в процессе изображения предметного содержания, осущест- вляется через обобщение, стилизацию и трансформацию конкретных изобразительных образов. Психологические исследования убедительно показывают, что становление зрительного образа происходит во взаимодействии с анализом художественных материалов и выбором композиционных форм его реализации, что представляет собой постепенное приближение к познанию сущности изображаемой модели (см. об этом: [1]). Проникновение в смысл и образную сущность изображаемого предмета, постижение гармоничности его формы является основой эстетического и художественного развития художников, которые на основе глубоких знаний, профессиональных умений, навыков обобщают, акцентируют, стилизуют, трансформируют в своих произведениях то или иное явление, передавая эмоционально-личностное отношение к нему.

Эстетическое начало существует реально и объективно, но проявляется только в процессе индивидуального, 